\title{
Influence of flow conditions on scour hole shape for pier groups
}

1 Christian Chreties MSC

Assistant Professor, Instituto de Mecánica de los Fluidos e Ingeniería Ambiental (IMFIA), Engineering School, Universidad de la República, Uruguay

2 Luis Teixeira PhD

Full Professor, Instituto de Mecánica de los Fluidos e Ingeniería

Ambiental (IMFIA), Engineering School, Universidad de la República, Uruguay
3 Gonzalo Simarro PhD

Associate Researcher, Instituto de Ciencias del Mar (CSIC), Spain
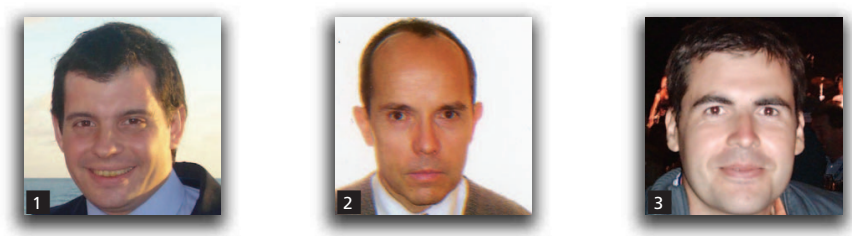

Local scour at alluvial bridge foundations is caused by the interference of the flow with the structure. The usual laboratory experiments set constant flow conditions and allow local scour to develop until the equilibrium stage, which can take several days. However, as long as the geometry of the scour hole is independent of the flow conditions used to obtain a given scour depth, faster experimental methods are available in the literature. In this paper the influence of flow conditions on the shape of the scour hole is investigated experimentally for different configurations of pile groups with and without pile cap. It is found that, whenever no pile cap is present, the angle of repose of the sediment dominates the geometry of the scour hole, regardless of flow conditions. On the contrary, in the presence of a pile cap, the geometry of the scour hole strongly depends on flow conditions.

\section{Notation}

$a, b, c$

$d$

$d_{\mathrm{s}}$

$d_{50}$

g

h

$L_{i}$

$l$

$m$

$q$

s

$t$

w

$\Gamma=s / d$

$\theta$

$v$

$\rho$

$\rho_{\mathrm{S}}$

$\sigma_{\mathrm{g}}$

$\phi$ characteristic lengths of the scour hole

pile diameter

local scour depth

median sediment size

acceleration due to gravity

water depth

characteristic lengths of the geometry of the pile cap (see Figure 2)

any length of the scour hole geometry

number of piles columns in the pile group (see

Figure 1)

number of piles rows in the pile group (see

Figure 1)

flow rate per unit width

pile group spacing (see Figure 1)

time

channel width

dimensionless pile group spacing

angle of the scour hole

water kinematic viscosity

water density

sediment density

granulometric sediment dispersion

arbitrary function $\varphi_{a}, \varphi_{b}, \lambda_{\mathrm{a}}, \lambda_{b}$ regression coefficients for $a$ and $b$ scour hole lengths

\section{Introduction}

Local scour at bridge piers is an important issue in civil engineering as it is the main reason for bridge collapse. Local scour is the engineering term for the erosion of the soil surrounding a bridge foundation (piers and abutments), which is the result of the erosive action of the flowing water, excavating and carrying away material from around the piers and abutments of bridges (Hoffmans and Verheij, 1997; Melville and Coleman, 2000; Richardson and Davis, 1991). The process combines the complexities of a three-dimensional flow pattern (characterised by different vortex systems around the structure) with suspended and bed sediment transport (see, for example, Kothyari et al. (2007)). The phenomenon has attracted the interest of many researchers and, because of its complexity, an experimental approach is the usual practice (Melville and Coleman, 2000).

Essentially there are two different strategies to account for local scour in alluvial bridges. The first assumes that scour will occur and designs the pier to be stable for the eroded bed condition. The second considers protecting the structure so as to reduce or eliminate local scour at the foot of the structure. 
For the first strategy, which is the focus of the present study, the equilibrium scour depth is of major interest since it is an upper bound for the scour depth in time. The estimation of the equilibrium scour characteristics at bridge foundation elements continues to be a concern for hydraulic engineers. One of the main problems is that, although equilibrium scour is a widely accepted concept, obtaining it in the laboratory is difficult because the experiments usually take over a week in order to obtain reliable results (Breusers et al., 1977; Melville and Chiew, 1999; Simarro et al., 2011).

Recently, Chreties et al. (2008) proposed a different methodology that enables local scour experiments to be reduced to only a few hours in the case of single bridge piers under uniform sediment and clear water conditions. Contrary to the usual, or 'canonical', experiments, the methodology proposed by Chreties et al. (2008) considers, in an inverse procedure, finding out what flow conditions correspond to a given equilibrium scour depth. The hypothesis behind the methodology is that the shape of the scour hole for a given scour depth does not depend on the flow conditions used to obtain the actual state, but only on the problem's geometry (pier geometry and flume width), sediment characteristics and the actual scour depth, $d_{\mathrm{s}}$, itself. This hypothesis is equivalent to assuming from the outset that the geometry of the scour hole has 'no memory' of the flow conditions.

Given the 'no memory' hypothesis, the validity of the methodology by Chreties et al. (2008) is straightforward. Furthermore, the same hypothesis is also behind the methods most commonly used to handle unsteady flow conditions (Chang et al., 2004; Hager and Unger, 2010; Lu et al., 2011; Mia and Nago, 2003).

It is usually assumed that the shape of scour hole is indeed independent of the flow conditions because it can be approximated by an inverted cone frustum with the slope corresponding to the sediment's angle of repose. This hypothesis has proven to work well for simple geometries such as single cylindrical piers. However, a single cylindrical pier is too simple a geometry and the use of pile groups under a cap that supports the pier column is becoming more and more popular in bridge design for physical and economical reasons (Coleman, 2005).

Aiming at extending the methodology proposed by Chreties et al. (2008) to pile groups, the goal of the present work is to analyse experimentally the geometry of the scour holes in pile groups and, in particular, whether the 'no memory' hypothesis is a reasonable approximation. For this propose, an experimental approach has been adopted.

The paper is organised into sections as follows: after this introduction, the details of the methodology and a description of the experimental set-up and process are given. In the subsequent section the experimental results are presented and, in the next section, a full discussion of these results is provided. The final section is devoted to some concluding remarks.

\section{Methodology and experimental set-up}

Following the dimensional analysis presented by Chreties et al. (2008), using the common hypothesis (viscous effects negligible, uniform sediment and $\rho_{\mathrm{s}} / \rho=2 \cdot 65=$ constant, with $\rho_{\mathrm{s}}$ and $\rho$ the sediment and water densities) and keeping the following dimensionless groups constant here for all the experiments

$\frac{d_{50}}{d}=0.026$
2. $\frac{d}{w}=0.084$

any length of the geometry of the scour hole denoted by $l$ can be written as

3. $\frac{l}{d}=\phi\left(\frac{d_{\mathrm{s}}}{d}, \frac{q}{d \sqrt{\mathbf{g} d}}, \frac{h}{d}, \frac{q t}{d^{2}}, n, \quad m, \Gamma, \frac{L_{i}}{d}\right)$

where $h$ is the upstream water depth, $d_{50}$ is the sediment median size, $d$ is the diameter of individual piles (see Figure 1), $w$ is the channel width, $q$ is the flow rate per unit width, $g$ is the acceleration due to gravity, $t$ is the time, and $n, m, \Gamma$ and $L_{i}$ are the variables defining the geometry of the pier, as shown in Figures 1 and 2.

The hypothesis to be validated experimentally is that the shape of the local scour hole is essentially unaffected by the flow
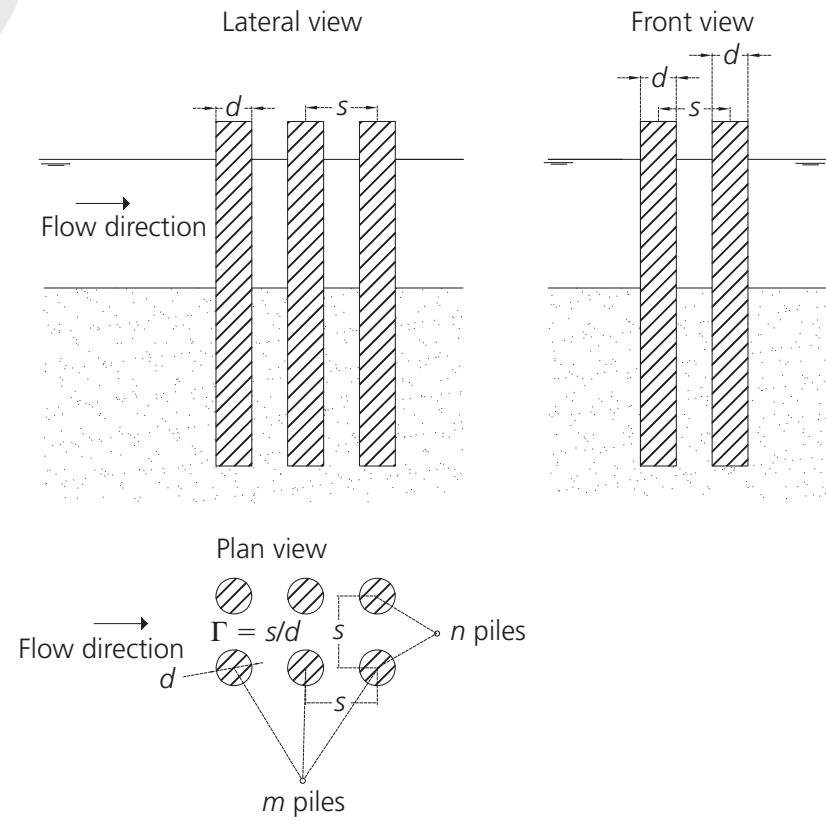

Figure 1. Piles group G1 model geometry 

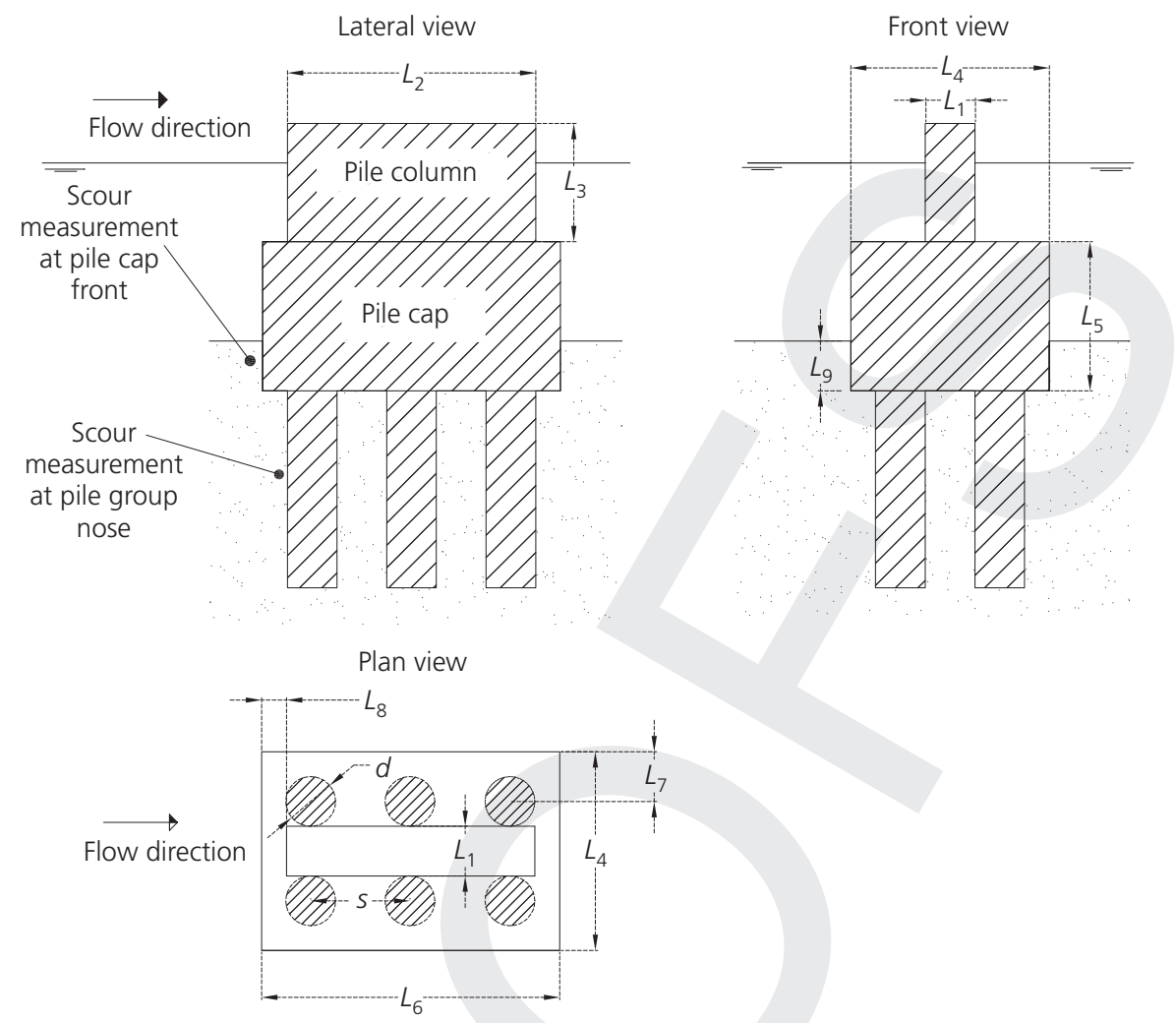

Figure 2. Complex pier G2 model geometry

conditions that generated it and, for a given geometry; it depends on the local scour $d_{\mathrm{s}}$ only. To prove this hypothesis, for any different geometry it should simply hold that

4. $\frac{l}{d}=\phi\left(\frac{d_{\mathrm{s}}}{d}\right)$

The experiments were carried out at the hydraulics laboratory of the Civil Engineering School at the University of Castilla-La Mancha (UCLM), Spain. A tilting flume $30 \mathrm{~m}$ long, $75 \mathrm{~cm}$ wide and $60 \mathrm{~cm}$ deep was used. This flume is the one already described by Chreties et al. (2008). The flume slope was set constant at $0 \cdot 01 \%$ in all experiments. The water depth was controlled through a tail-gate downstream. The tail-gate is step driven and every step provokes a change in water depth of approximately $4 \mathrm{~mm}$, which is always less than $5 \%$ of the water depth. An electromagnetic flowmeter with an accuracy of $1 \%$ was used to establish the flow rate. The water depth, scour depth and other scour hole lengths were measured using point gauges with a resolution of $0.1 \mathrm{~mm}$. Bed sediment is a quartzitic sand with $\rho_{\mathrm{s}}=2650 \mathrm{~kg} / \mathrm{m}^{3}$, $d_{50}=1.65 \mathrm{~mm}$ and granulometric dispersion $\sigma_{\mathrm{g}}=1.27$ (uniform).

Two different cases were tested: pile groups without a pile cap (G1, Figure 1) and with a cap (G2, Figure 2). For the cases G1, different geometries were considered, varying $n, m$ and $\Gamma$. In all G1 cases $d=6.3 \mathrm{~cm}$ while $n \times m$ values were $1 \times 3,2 \times 1$, $2 \times 3$ and $\Gamma=2,3,4$. The notation ' $\mathrm{G} 1 \_n m \Gamma$ ' is used to identify these experiments in Tables 1 and 2. The range of values of $\Gamma$ (particularly $2<\Gamma<3$ ) is a usual practice in engineering and the group effect is likely to play a role. In fact, according to AtaieAshtiani and Beheshti (2006), for $\Gamma>3$ the group effect is negligible and for $\Gamma=2$ the scour depth is $25 \%$ higher than that for a single pier.

For the G2 case (with a cap, Figure 2), only $n \times m=2 \times 3$, $\Gamma=2$ and $d=6.3 \mathrm{~cm}$ was considered. The variables defining G2 are shown in Figure 2, and the parameters were set $\mathrm{L} 1=d$, $L_{2}=5 d, L_{3}=2 \cdot 5 d, L_{4}=4 d, L_{5}=3 d, L_{6}=6 d, L_{7}=d, L_{8}=d / 2$, $L_{9}=d$.

All the experiments were carried out under clear water conditions. In each test, the local scour hole is generated using given flow conditions, which remained constant throughout the experiment. The scour depth and two other characteristic lengths of the scour hole ( $a$ and $b$ in Figure 3 ) were measured during the scour process so as to determine whether the characteristic lengths correlate well with $d_{\mathrm{s}}$ regardless of the flow conditions and time, in other words regardless of $q / d(g d)^{0.5}, h / d$ and $q t / d^{2}$ in Equation 3. In the experiments, $a$ and $b$ were measured using two point gauges, one at the pier and the other at the edge of the scour 


\begin{tabular}{|c|c|c|c|c|c|c|c|}
\hline Experiment code & $d: m$ & $n$ & $m$ & $\Gamma$ & $h / d$ & $q / d(g d)^{0.5}$ & $q t / d^{2}$ \\
\hline G1_132_T01 & 0.063 & 1 & 3 & 2 & $4 \cdot 50$ & $2 \cdot 24$ & $5.15 \times 10^{5}$ \\
\hline G1_132_T02 & 0.063 & 1 & 3 & 2 & $4 \cdot 50$ & $2 \cdot 24$ & $4.02 \times 10^{5}$ \\
\hline G1_132_T03 & 0.063 & 1 & 3 & 2 & $4 \cdot 50$ & $2 \cdot 24$ & $4.02 \times 10^{5}$ \\
\hline G1_132_T04 & 0.063 & 1 & 3 & 2 & $1 \cdot 60$ & $0 \cdot 70$ & $6.60 \times 10^{5}$ \\
\hline G1_132_T05 & 0.063 & 1 & 3 & 2 & 3.25 & $1 \cdot 16$ & $3.52 \times 10^{6}$ \\
\hline G1_132_T06 & 0.063 & 1 & 3 & 2 & $1 \cdot 60$ & 0.54 & $1.12 \times 10^{6}$ \\
\hline G1_134_T01 & 0.063 & 1 & 3 & 4 & $4 \cdot 50$ & $2 \cdot 24$ & $4.03 \times 10^{5}$ \\
\hline G1_134_T02 & 0.063 & 1 & 3 & 4 & $4 \cdot 50$ & $2 \cdot 24$ & $4.10 \times 10^{5}$ \\
\hline G1_134_T03 & 0.063 & 1 & 3 & 4 & $4 \cdot 50$ & $2 \cdot 24$ & $4.12 \times 10^{5}$ \\
\hline G1_134_T04 & 0.063 & 1 & 3 & 4 & $1 \cdot 60$ & 0.70 & $8.68 \times 10^{5}$ \\
\hline G1_134_T05 & 0.063 & 1 & 3 & 4 & 3.25 & $1 \cdot 16$ & $3.77 \times 10^{6}$ \\
\hline G1_134_T06 & 0.063 & 1 & 3 & 4 & $1 \cdot 60$ & 0.54 & $1.08 \times 10^{6}$ \\
\hline G1_212_T01 & 0.063 & 2 & 1 & 2 & $4 \cdot 50$ & $2 \cdot 24$ & $4.08 \times 10^{5}$ \\
\hline G1_212_T02 & 0.063 & 2 & 1 & 2 & $4 \cdot 50$ & $2 \cdot 24$ & $4.08 \times 10^{5}$ \\
\hline G1_212_T03 & 0.063 & 2 & 1 & 2 & $4 \cdot 50$ & $2 \cdot 24$ & $4.02 \times 10^{5}$ \\
\hline G1_212_T04 & 0.063 & 2 & 1 & 2 & $1 \cdot 60$ & 0.70 & $6.70 \times 10^{5}$ \\
\hline G1_212_T05 & 0.063 & 2 & 1 & 2 & $3 \cdot 25$ & $1 \cdot 16$ & $3.62 \times 10^{6}$ \\
\hline G1_212_T06 & 0.063 & 2 & 1 & 2 & $1 \cdot 60$ & 0.54 & $1.11 \times 10^{6}$ \\
\hline G1_214_T01 & 0.063 & 2 & 1 & 4 & 4.50 & $2 \cdot 24$ & $4.89 \times 10^{5}$ \\
\hline G1_214_T02 & 0.063 & 2 & 1 & 4 & $4 \cdot 50$ & $2 \cdot 24$ & $4.08 \times 10^{5}$ \\
\hline G1_214_T03 & 0.063 & 2 & 1 & 4 & 4.50 & $2 \cdot 24$ & $4.02 \times 10^{5}$ \\
\hline G1_214_T04 & 0.063 & 2 & 1 & 4 & $1 \cdot 60$ & 0.70 & $6.60 \times 10^{5}$ \\
\hline G1_214_T05 & 0.063 & 2 & 1 & 4 & 3.25 & $1 \cdot 16$ & $3.63 \times 10^{6}$ \\
\hline G1_214_T06 & 0.063 & 2 & 1 & 4 & $1 \cdot 60$ & 0.54 & $1.13 \times 10^{6}$ \\
\hline G1_233_T01 & 0.063 & 2 & 3 & 3 & $4 \cdot 50$ & $2 \cdot 24$ & $4.60 \times 10^{5}$ \\
\hline G1_233_T02 & 0.063 & 2 & 3 & 3 & $4 \cdot 50$ & $2 \cdot 24$ & $4.56 \times 10^{5}$ \\
\hline G1_233_T03 & 0.063 & 2 & 3 & 3 & $4 \cdot 50$ & $2 \cdot 24$ & $4.65 \times 10^{5}$ \\
\hline G1_233_T04 & 0.063 & 2 & 3 & 3 & $1 \cdot 60$ & 0.70 & $7 \cdot 11 \times 10^{5}$ \\
\hline G1_233_T05 & 0.063 & 2 & 3 & 3 & $3 \cdot 25$ & $1 \cdot 16$ & $3.67 \times 10^{6}$ \\
\hline G1_233_T06 & 0.063 & 2 & 3 & 3 & $1 \cdot 60$ & 0.54 & $1.11 \times 10^{6}$ \\
\hline G2_232_T01 & 0.063 & 2 & 3 & 2 & $4 \cdot 50$ & $2 \cdot 24$ & $3.95 \times 10^{5}$ \\
\hline G2_232_T02 & 0.063 & 2 & 3 & 2 & $4 \cdot 50$ & $2 \cdot 24$ & $4.07 \times 10^{5}$ \\
\hline G2_232_T03 & 0.063 & 2 & 3 & 2 & $3 \cdot 25$ & $1 \cdot 16$ & $3.60 \times 10^{6}$ \\
\hline G2_232_T04 & 0.063 & 2 & 3 & 2 & $3 \cdot 25$ & $1 \cdot 16$ & $4.86 \times 10^{6}$ \\
\hline G2_232_T05 & 0.063 & 2 & 3 & 2 & $1 \cdot 60$ & 0.7 & $8.22 \times 10^{5}$ \\
\hline
\end{tabular}

Table 1. Experimental flow conditions

hole, and a ruler to measure the horizontal distance between them.

The variation ranges of the above-mentioned dimensionless groups corresponding to flow conditions and time were (Table 1)

5. $1 \cdot 60 \leqslant \frac{h}{d} \leqslant 4 \cdot 50$

6. $0.54 \leqslant \frac{q}{d \sqrt{g d}} \leqslant 2 \cdot 24$
7. $2 \times 10^{2} \leqslant \frac{q t}{d^{2}} \leqslant 5 \times 10^{6}$

Experimental conditions for G1 (30 tests) and G2 (five tests) are shown in Table 1. In order to measure the system's inner noise, that is the differences in the results due to measurement errors, some experiments were performed under identical flow conditions for each geometry, for each G1_nm $\Gamma$. The repeated tests are the first three for each group G1_nm $\Gamma$ in Table 1.

The scour depth at the nose of the first pile of the group (and also at the front of the pile cap for geometries G2), $a$ and $b$ were measured after $1,2 \cdot 5,5,7 \cdot 5,10,15,20,30,45,60,90,120,150$, 


\begin{tabular}{|c|c|c|c|c|c|c|c|c|}
\hline Pier type & Distance & $\varphi(a, b) 95 \%$ conf. & $\lambda(a, b) 95 \%$ conf. & $R$ & RMSE (full) & $\begin{array}{c}\text { RMSE } \\
\text { (repeated) }\end{array}$ & $c / d$ & $\theta$ : degrees \\
\hline \multirow[t]{2}{*}{ Single, cylindrical } & $a / d$ & $1 \cdot 3364 \pm 0.014$ & $0.1183 \pm 0.011$ & 0.9940 & 0.046 & 0.046 & 0.12 & 37 \\
\hline & $b / d$ & $1 \cdot 2833 \pm 0.017$ & $0.5927 \pm 0.015$ & 0.9900 & 0.058 & 0.055 & & \\
\hline \multirow[t]{2}{*}{ G1_132 } & $a / d$ & $1.2173 \pm 0.026$ & $0.1854 \pm 0.028$ & 0.9940 & 0.061 & 0.064 & 0.19 & 39 \\
\hline & $b / d$ & $1.3633 \pm 0.031$ & $0.4722 \pm 0.033$ & 0.9940 & 0.073 & 0.074 & & \\
\hline \multirow[t]{2}{*}{ G1_134 } & $a / d$ & $1 \cdot 2696 \pm 0.022$ & $0.1230 \pm 0.020$ & 0.9970 & 0.037 & 0.036 & 0.12 & 38 \\
\hline & $b / d$ & $1.3754 \pm 0.031$ & $0.5181 \pm 0.029$ & 0.9940 & 0.054 & 0.068 & & \\
\hline \multirow[t]{2}{*}{ G1_212 } & $a / d$ & $1 \cdot 3074 \pm 0.029$ & $0.1023 \pm 0.033$ & 0.9940 & 0.062 & 0.071 & $0 \cdot 10$ & 37 \\
\hline & $b / d$ & $1.3267 \pm 0.029$ & $0.5353 \pm 0.032$ & 0.9950 & 0.060 & 0.065 & & \\
\hline \multirow[t]{2}{*}{ G1_214 } & $a / d$ & $1.3518 \pm 0.032$ & $0.0770 \pm 0.034$ & 0.9930 & 0.073 & 0.062 & 0.08 & 36 \\
\hline & $b / d$ & $1.3550 \pm 0.036$ & $0.4843 \pm 0.038$ & 0.9910 & 0.082 & 0.065 & & \\
\hline \multirow[t]{2}{*}{ G1_223 } & $a / d$ & $1.2109 \pm 0.021$ & $0.2067 \pm 0.023$ & 0.9960 & 0.052 & 0.060 & 0.21 & 40 \\
\hline & $b / d$ & $1 \cdot 2462 \pm 0.022$ & $0.7502 \pm 0.024$ & 0.9960 & 0.054 & 0.057 & & \\
\hline \multirow[t]{2}{*}{ All G1 data } & $a / d$ & $1 \cdot 2727 \pm 0.013$ & $0.1397 \pm 0.014$ & 0.9935 & 0.065 & 0.065 & 0.14 & 38 \\
\hline & $b / d$ & $1.3337 \pm 0.019$ & $0.5539 \pm 0.020$ & 0.9875 & 0.095 & 0.088 & & \\
\hline
\end{tabular}

Table 2. Experimental results for pile groups G1 models
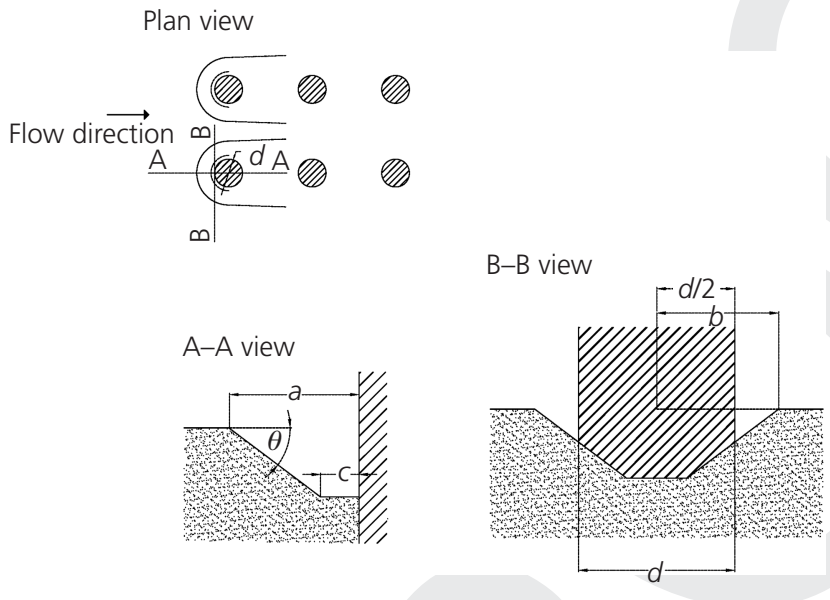

Figure 3. Scour and characteristics length measurement in scour hole

180, 220, $250 \mathrm{~min}$ and further for each experiment. Some experiments lasted for several days (especially those under weak flow conditions). The experiments, however, were not aimed at attaining equilibrium conditions.

\section{Experimental results}

Figure 4 shows the local scour time evolution results for all G1_134 experiments. the different behaviour of the experiments in this figure was noted, since different flow conditions are used and some experiments will obtain much higher scour depth values than others. However, when plotting a/d (or $b / d$ ) against $d_{\mathrm{s}} / d$ almost linear relationships were obtained, which are essentially independent of the flow conditions for G1 (Figure 5, where the variable time has dropped). The following may be written

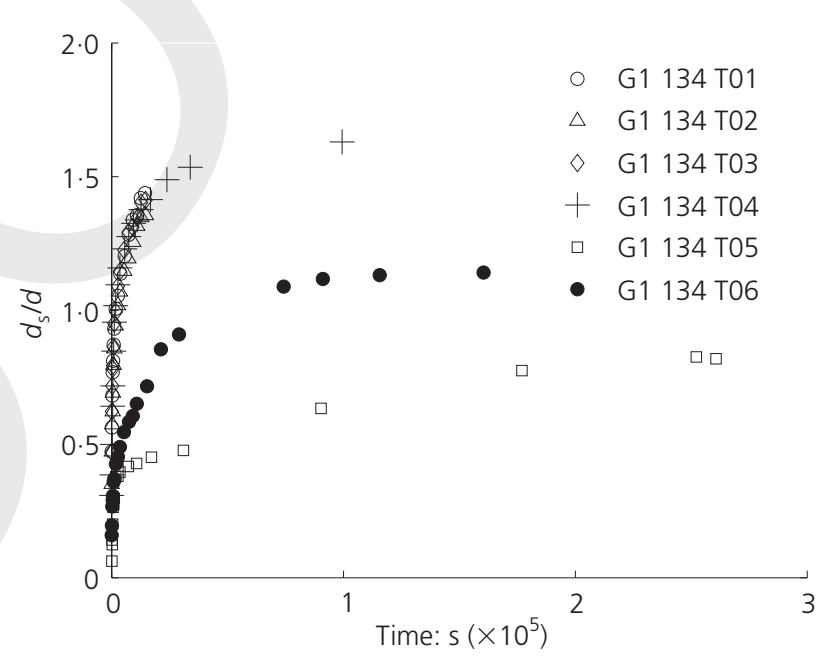

Figure 4. Temporal evolution of scour depth for all G1_134 geometry: G1_134_T01 (white circles); G1_134_T02 (triangles); G1_134_T03 (diamonds); G1_134_T04 (crosses); G1_134_T5 (squares); and G1_134_T6 (black circles)

8. $\frac{a}{d}=\lambda_{a}+\varphi_{a} \frac{d_{\mathrm{s}}}{d}$

9. $\frac{b}{d}=\lambda_{b}+\varphi_{b} \frac{d_{\mathrm{s}}}{d}$

The averaged regression coefficients $\lambda_{a}, \lambda_{b}, \varphi_{a}$ and $\varphi_{b}$ for each G1_nm $\Gamma$ appear in Table 2. Table 2 also includes the correlation coefficient $(R)$, the root mean square error (RMSE) and the limit of $95 \%$ confidence interval for each coefficient. 


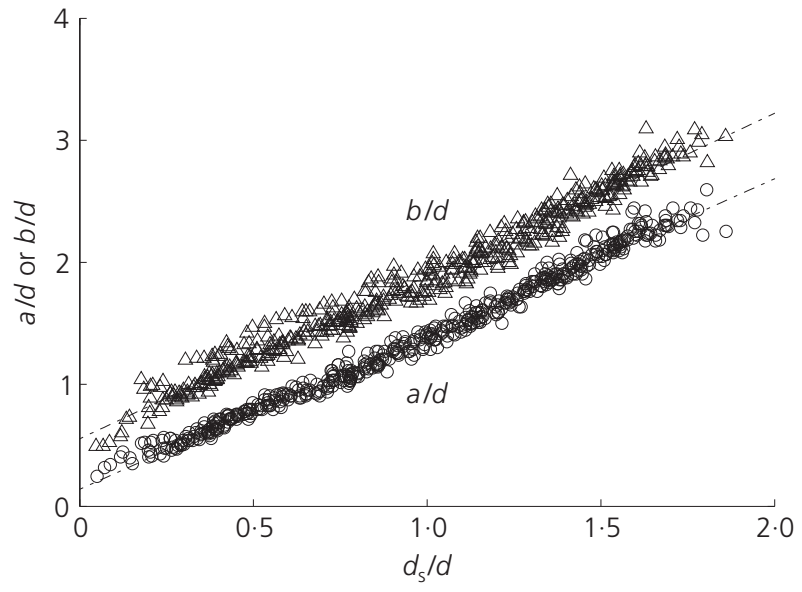

Figure 5. Characteristic length a/d and b/d plotted against scour depth $d s / d$ for all G1 geometry experiments: a/d (circles), b/d (triangles), linear regression (dashed line)

Ignoring the differences between different geometries, which are otherwise small, the points in Figure 4 can be fitted by

10. $\frac{a}{d}=0 \cdot 1397+1 \cdot 2727 \frac{d_{\mathrm{s}}}{d}$

11. $\frac{b}{d}=0.5539+1 \cdot 3337 \frac{d_{\mathrm{s}}}{d}$ where the global correlation coefficients are, respectively, $R=0.994$ and with $R=0.988$ (Table 2).

Finally, for G2, Figure 6 shows a/d plotted against the normalised scour depth $d_{\mathrm{s}} / d$ measured in front of the pile cap for all five different experiments. Figure 7 also shows ald plotted against $d_{\mathrm{s}} / d$, but in this case the scour depth is measured at the nose of the pile group. Black symbols correspond to repeated experiments.

\section{Discussion}

In order to verify the 'no memory' hypothesis it is sufficient to prove that $l / d$ can be determined from $d_{\mathrm{s}} / d$ for a given geometry. According to the above results (Figure 5 and Table 2) this is indeed true for all G1 geometries, based on RMSEs shown in Table 2. It may be remarked that, for each G1 geometry, the RMSE obtained for all experiments is the same order of magnitude as those for the three repeated experiments (seventh column in Table 2), so that the influence of the flow conditions, if any, is indistinguishable from the noise of the system.

As mentioned above, $l / d$ are essentially linear functions of $d_{\mathrm{s}} / d$ for each G1 geometry. The least-squares fit method presented high correlation coefficients, $R$ greater than 0.991 . Table 2 also shows the $95 \%$ confidence fit intervals values.

Regarding G1 cases, a brief discussion of the shape of functions a/d and $b / d$ against $d_{\mathrm{s}} / d$ is pertinent here. According to Figure 3

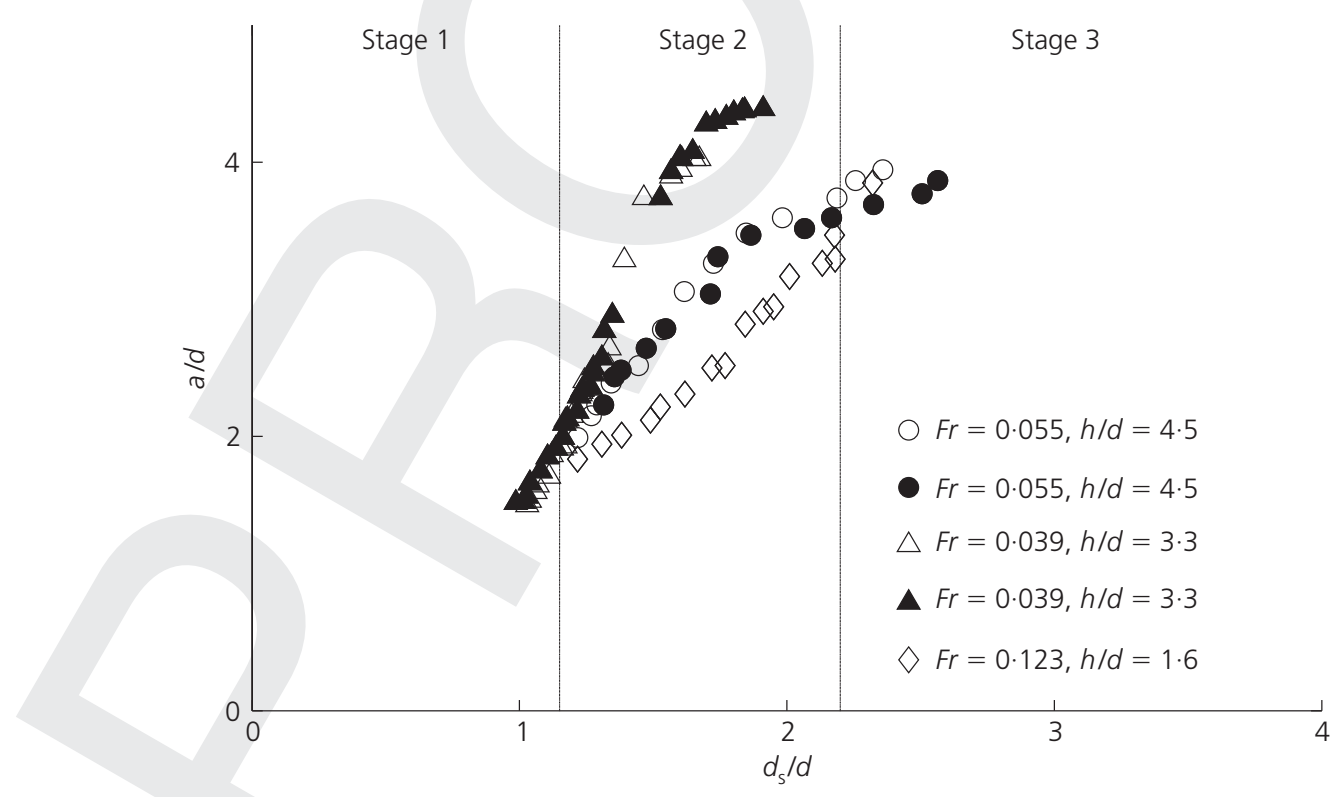

Figure 6. Characteristic length a/d plotted against the normalised scour depth $d_{s} / d$ measured in front of pile cap (G2 model): G2_232_T01 (white circles); G2_232_T02 (black circles);

G2_232_T03 (white triangles); G2_232_T04 (black triangles);

G2_232_T05 (diamonds) 


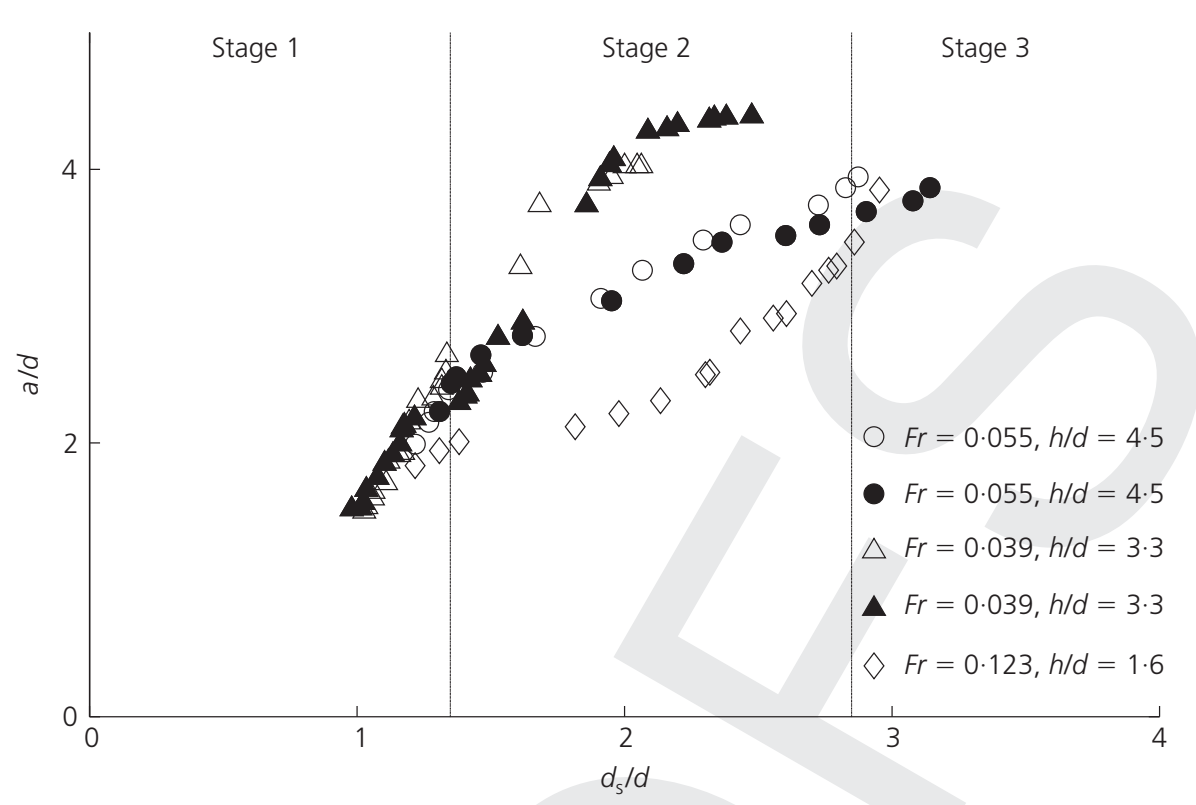

Figure 7. Characteristic length a/d plotted against the normalised scour depth $d_{\mathrm{s}} / d$ measured at the nose of the pile group ( $G 2$ model): G2_232_T01 (white circles); G2_232_T02 (black circles);

G2_232_T03 (white triangles); G2_232_T04 (black triangles);

G2_232_T05 (diamonds)

12. $a=c+\frac{d_{\mathrm{s}}}{\tan \theta}$

Equation 12 justifies the linear behaviour for a/d proposed in Equation 8. Further, comparing both expressions

13. $c=\lambda_{a} d$

and

14. $\varphi_{a}=\frac{1}{\tan \theta}$

and therefore, $c$ and $\theta$ can be recovered for each geometry (Table 2).Equation 13 and the results for $c$ are consistent with those of Mia and Nago (2003) and Bateman et al. (2005). In both references, the proposed value of $c$ is around half the pier diameter $d$. Additionally, the $\theta$ angle obtained for each geometry in Table 2 is very close to the measured friction angle for the sediment bed, which was $38^{\circ}$.

Although the differences in the coefficients between different geometries are small, it is possible to identify that $c$ and $\theta$ slightly increase with $m$ and decrease with nor $\Gamma$. These trends are very mild and, in any case, they do not invalidate the "no memory' hypothesis.
For individual circular piers, it has been suggested that the upstream part of scour hole geometry can be modelled by an inverted cone frustum ( $\mathrm{Lu}$ et al., 2011; Melville and Coleman, 2000; Mia and Nago, 2003). Assuming this geometry, from Figure 3 it should hold

15. $b=\sqrt{a d+a^{2}}$

which, for 'small' values of $d / a$, can be approximated as

16. $b=a\left(1+\frac{d}{2 a}\right)$

Figure 8 shows $a$ plotted against $b$ for all G1 experiments overlapped together with the expressions for Equations 15 and 16 , showing a good agreement.

The above result also explains the behaviour of $b / d$ plotted against $d_{\mathrm{s}} / d$, since now it should hold that

17. $\frac{b}{d} \approx \frac{a}{d}\left(1+\frac{d}{2 a}\right)=\frac{a}{d}+\frac{1}{2}$

so that 


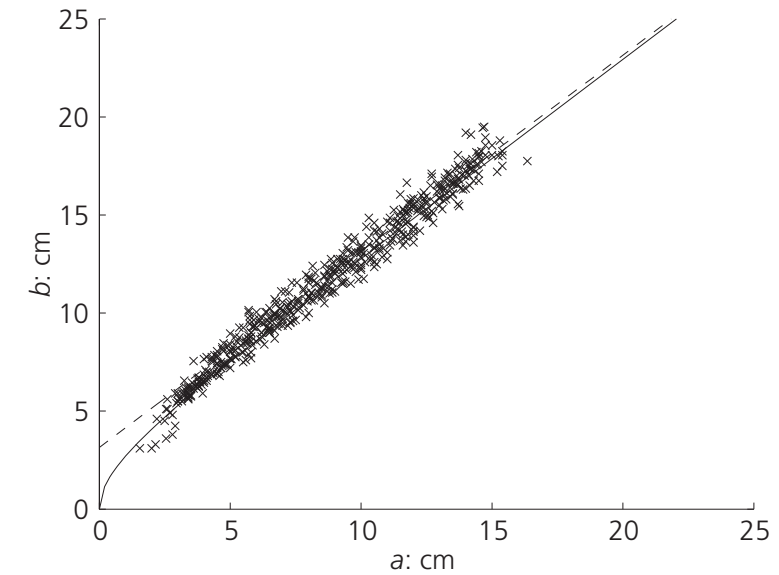

Figure 8. Analysis of the scour hole geometry for all G1 model experiments results. Direct $a$ and $b$ measurement compared to Equation 15 (line) and Equation 16 (dashed line)

18. $\lambda_{b}=\lambda_{a}+\frac{1}{2}$

and

19. $\varphi_{a}=\varphi_{b}$

From the experimental data (Table 2), considering the averaged values

20. $\lambda_{b}-\lambda_{a}=0.42$

21. $\frac{\varphi_{b}}{\varphi_{a}}=1 \cdot 04$

which is consistent with the theoretical results in Equations 18 and 19 .

Figures 6 and 7 show the results for the tests corresponding to case G2 (with a cap and always being $n \times m=2 \times 3$ and $\Gamma=2$ ) using two different measurements for the scour depth. The results include in this case two pairs of repeated experiments (Table 1).

Two different stages are clearly observed in this case. As long as the pile group is not yet exposed to flow, a linear trend is found for a/d plotted against $d_{\mathrm{s}} / d$; the scour process at this stage resembles that of an isolated rectangular pier (the whole pile cap), and the 'no-memory' hypothesis is satisfied. In a second stage, the pile group is exposed to flow and no linear trend of a/d plotted against $d_{\mathrm{s}} / d$ is obtained. In fact, the results now become quite different, depending on flow conditions. The hydraulic
Froude number appears to have the main influence in this case (Figures 6 and 7): given a scour depth $d_{\mathrm{s}} / d$, the length a/d for $F r=0.123$ is half that for $F r=0.039$. As the scour process continues, pile groups are increasingly exposed to the flow, and the pile cap scour relevance decreases. Only if the flow conditions were sufficiently strong, a third stage could be expected where the pile cap scour effect would become irrelevant, depending on flow conditions. However, this third stage was not clearly identified in the experiments.

Therefore, for G2, the shape of the scour hole is not independent of the flow conditions and, hence, the results of Chreties et al. (2008) for equilibrium scour and the method by Chang et al. (2004) for temporal scour evolution under unsteady flows, are not applicable.

\section{Concluding remarks}

The 'no memory' hypothesis has been experimentally studied for different pier groups. This hypothesis was validated for all configurations where the pile cap did not interfere with the flow (G1 cases). Furthermore, for these geometries, similar to the case of single piers, the sediment's friction angle dominates the geometry of the scour hole and the influence of the pier arrangement is small. This result allows the methodology by Chreties et al. (2008) to be used to find equilibrium scour depth, and also the usual methodologies to compute local scour under unsteady flows (Chang et al., 2004). On the contrary, the experimental results show that whenever the pile cap is involved in the scour process, the geometry does depend explicitly on flow conditions, so that the hypothesis is not verified.

\section{Acknowledgements}

Christian Chreties was supported by the Agencia Nacional de Investigación e Innovación (ANII) from Uruguay. The authors would like thank Eduardo Díaz for his help in preparing the experiments.

\section{REFERENCES}

Ataie-Ashtiani B and Beheshti AA (2006) Experimental investigation of clear-water local scour at pile groups. Journal of Hydraulic Engineering, ASCE 132(10): $1100-$ 1104.

Bateman A, Fernández M and Parker G (2005) Morphodynamic model to predict temporal evolution of local scour in bridge piers. Proceedings of the 4th IAHR Symposium on River, Coastal and Estuarine Morphodynamics (RCEM). Taylor and Francis/Balkema, pp. 911-920.

Breusers HNC, Nicollet G and Shen HW (1977) Local scour around cylindrical piers. Journal of Hydraulic Research 15(3): 211-252.

Chang WY, Lai JS and Yen CL (2004) Evolution of scour depth at circular bridge piers. Journal of Hydraulic Engineering, ASCE 130(9): 905-913.

Chreties C, Simarro G and Teixeira L (2008) New experimental method to find equilibrium scour at bridge piers. Journal of Hydraulic Engineering, ASCE 134(10): 1491-1496. 
Coleman S (2005) Clearwater local scour at complex piers. Journal of Hydraulic Engineering, ASCE 131(4): 330-334.

Hager WH and Unger J (2010) Bridge pier scour under flood waves. Journal of Hydraulic Engineering, ASCE 136(10): 842-847.

Hoffmans GJCM and Verheij HJ (1997) Scour Manual. AA Balkema, Rotterdam, The Netherlands.

Kothyari UC, Hager WH and Oliveto G (2007) Generalized approach for clear-water scour at bridge foundation elements. Journal of Hydraulic Engineering, ASCE 133(11): 1229-1240.

Lu J, Zhong-Zhi S, Jian-Hao H, Jun-Ji L and Rajkumar VR (2011) Temporal variation of scour depth at nonuniform cylindrical piers." Journal of Hydraulic Engineering, ASCE 137(1): $45-56$.
Melville BW and Chiew Y (1999) Time scale for local scour at bridge piers. Journal of Hydraulic Engineering, ASCE 125(1): 59-65.

Melville BW and Coleman SE (2000) Bridge Scour. Water Resources Publications, LLC, Colorado, USA.

Mia MF and Nago H (2003) Design method of time-dependent local scour at circular bridge pier. Journal of Hydraulic Engineering, ASCE 129(6): 420-427.

Richardson E and Davis S (2001) Evaluating Scour at Bridges. Federal Highway Administration (FHWA), Washington, D.C., USA.

Simarro G, Fael CMS and Cardoso AH (2011) Estimating equilibrium scour depth at cylindrical piers in experimental studies. Journal of Hydraulic Engineering, ASCE in press.
1: Please check/provide three keyword terms from ICE approved list at http://www.icevirtuallibrary.com/upload/proceedingskeywords.pdf

2: Please check correct year of publication Richardson and Davis, 1991 in text, 2001 in refs list

3: Is this the correct figure citation here, or should it be 5 ?

4: Are you able to provide an update with vol/issue and page numbers now?

\section{WHAT DO YOU THINK?}

To discuss this paper, please email up to 500 words to the editor at journals@ice.org.uk. Your contribution will be forwarded to the author(s) for a reply and, if considered appropriate by the editorial panel, will be published as a discussion in a future issue of the journal.

Proceedings journals rely entirely on contributions sent in by civil engineering professionals, academics and students. Papers should be 2000-5000 words long (briefing papers should be 1000-2000 words long), with adequate illustrations and references. You can submit your paper online via www.icevirtuallibrary.com/content/journals, where you will also find detailed author guidelines. 